\section{SOI: 1.1/TAS DOI: 10.15863/TAS International Scientific Journal Theoretical \& Applied Science}

\author{
p-ISSN: 2308-4944 (print) \\ e-ISSN: 2409-0085 (online) \\ Year: 2015 \\ Issue: 08 \\ Volume: 28
}

Published: $30.08 .2015 \quad \underline{\text { http://T-Science.org }}$

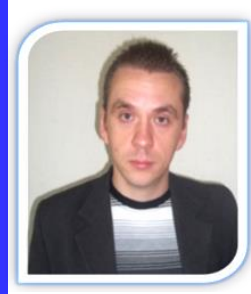

Denis Alexandrovich Chemezov Master of Engineering and Technology, Corresponding member of International Academy of

Theoretical and Applied Sciences, Lecturer of Vladimir Industrial College,

Russia

chemezov-da@yandex.ru

SECTION 7. Mechanics and machine construction.

\title{
THE RELIABILITY OF THE INTERFERENCE FIT
}

Abstract: The article considers the character of the pairing contact surfaces of the two bushings, made of alloy steel and aluminum alloy, with the guaranteed tightness $(N=0.03 \mathrm{~mm})$ when pressing-in details at cold condition. The highest stress of the material is observed on the inner surface of the bushing of alloy steel in the direction of the coordinate axis $Z$ on the part action of the efforts of pressing-in. This increases the strength of adhesion of the surfaces of the bushings on that side. Presents a comprehensive picture of changes in the direction of the velocity of deformation of materials in the longitudinal and transverse cross sections are pressed bushings. The maximum value of kinetic/internal energy ratio for bushing made of alloy steel is 22 at the end of the time range of the process of pressing-in.

Key words: bushing, pressing-in, stress, aluminium alloy, alloy steel.

Language: English

Citation: Chemezov DA (2015) THE RELIABILITY OF THE INTERFERENCE FIT. ISJ Theoretical \& Applied Science 08 (28): 65-69.

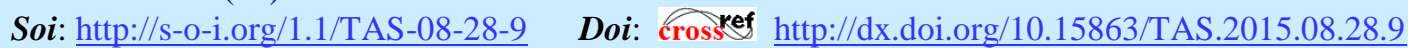

\section{INTRODUCTION}

An interference fit is a fixed non-detachable connection of the details. On contact surfaces of the pressing-in details occurs of the friction force which ensures the fixed of the assembly. The process of pressing-in accompanied by elastic-plastic deformation of the details at the pairing. The difference of the pairing diameters of the details and conditions of pressing-in, along with other factors, will determine the strength of the connection and the character of the deformation of surfaces.

The influence of the value of the tightness on the strength of the connection was thoroughly research in various scientific articles. The strength of the interference fit of brittle materials (cast iron) is achieved subject to the limitations during temperature assembly, provided that the value of hoopential stresses of the details do not exceed the yield strength of the material [1]. In another article it was determined that pressing-in of details with $\mathrm{N}=$ $0.08 \mathrm{~mm}$ of uniform materials (alloy steel) a higher intensity of deformation and stress of the materials of the details occurs from the side of pressing-in [2]. In scientific work [3] calculated that the average value of the contact pressure in the connection of the details of different lengths the more than less the length of pairing. In article [4] considered the influence of factors on the actual contact area of the details with tightness: with the increase of the nominal diameter of the pairing surface the value relative the contact area continuously decreases. Final grinding of the contact surfaces of the details allows to reduce $\mathrm{N}$ to 2 times compared to the turning at the same strength of connection [5].

This article presents the results of computer calculation of stress-strain state of dissimilar materials of the details expose to pressing-in.

\section{MATERIALS AND METHODS}

The objects of the research were two bushings, which connected at the outer and inner surfaces with tightness $\mathrm{N}$ by application of force $\mathrm{F}$ to the end surface of the detail made of aluminum alloy. The value of the guaranteed tightness adopted $0.03 \mathrm{~mm}$, it is recommended when operating of interference fit under the action of medium alternating loads. F accepted value of $5 \mathrm{kN}$, the direction along the centerline of the bushings.

As the materials of bushings have been adopted aluminum alloy [6] (mass density $\rho=2770 \mathrm{~kg} / \mathrm{m}^{3}$, Young's modulus $\mathrm{E}=71000 \mathrm{MPa}$, Poisson's ratio $\mu=$ 0.33 , yield stress $\sigma_{\mathrm{T}}=120 \mathrm{MPa}$, tangent modulus $\mathrm{G}$ $=25500 \mathrm{MPa})$ and alloy steel [7] $\left(\rho=7850 \mathrm{~kg} / \mathrm{m}^{3}, \mathrm{E}\right.$ $=200000 \mathrm{MPa}, \mu=0.3, \sigma_{\mathrm{T}}=785 \mathrm{MPa}, \mathrm{G}=79300$ $\mathrm{MPa})$. The configuration, orientation and sizes of the solid models of the bushings are presented in Fig 1. 
The bushing made of alloy steel is adopted fixed body. The bushing made of aluminum alloy is moved only in the axial direction. Pressing-in bushing were carried out in cold condition.

Simulation of the process of pressing-in performed in the software environment LS-DYNA. The relatively high accuracy of the calculation was achieved by partitioning solid models into finite elements: the bushing made of alloy steel - 65637 elements, the bushing made of aluminum alloy 18360 elements. The character of the mating surfaces of the bushings recorded in the keyword *CONTACT_AUTOMATIC_SINGLE_SURFACE taking into account of the viscous damping coefficient of $10 \%$.

The process of simulation was accompanied of parameters by control solutions [8]: the number of cycles -100000 , reduction factor for initial time step size to determine minimum time step -0.01 , percent change in energy ratio for termination of calculation $-10 \%$, scale factor for computed time step - 0.9, hourglass viscosity type - standard LS-DYNA, hourglass coefficient -0.1 , quadratic viscosity coefficient -1.5 , linear viscosity coefficient -0.06 , bulk viscosity type --2 , penalty stiffness - minimum of master segment and slave node, hourglass energy calculation - energy is computed and included in the energy balance, Hughes-Lui normal computation normal each cycle, shell formulation basis Belytschko-Tsay, integration for shell through thickness - Gauss, convergence check interval - 250, convergence tolerance for dynamic relaxation 0.001 , dynamic relaxation factor -0.995 , particle approximation - standard gather form, the duration of the simulation of the process of pressing-in -1.14 s.

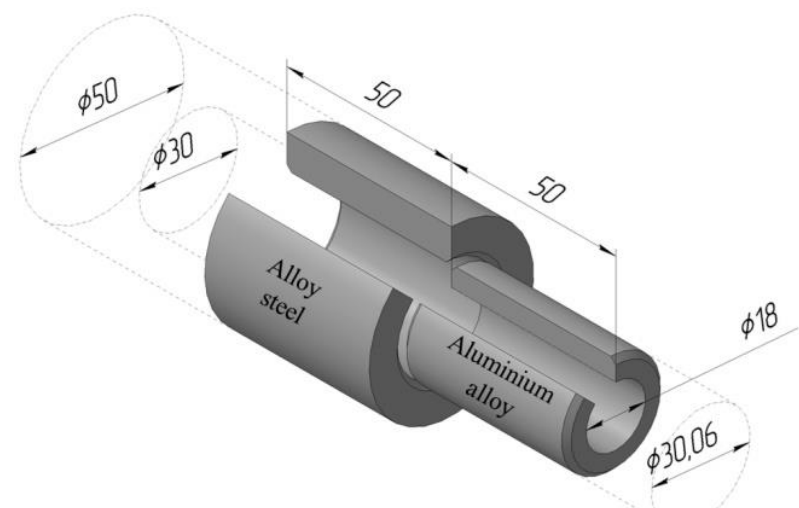

Figure 1 - The orientation and sizes of the solid models of bushings to the implementation of the simulation of the process of pressing-in. The size of the chamfer, $1.5 \times 45^{\circ}$.

\section{RESULTS AND DISCUSSION}

The results of simulation of the process of pressing-in presented in the form of color contours on the surfaces of the models, which characterize the intensity of the stress state of the bushings (Fig 2).

Stress of materials in contact surfaces of the bushings are considered along three coordinate axes $\mathrm{X}, \mathrm{Y}$ and $\mathrm{Z}$.

The size and distribution of $\mathrm{X}$-stress will depend on the action of the force of pressing-in. Red highlighted area of the contact surface of the bushing made of alloy steel where there is a significant tensile. The bushing made of aluminum alloy exposed to compression. The value of $\mathrm{X}$-stress changes in the material at a characteristic local areas.

Y-stress on the contact surfaces of the bushings is $-5 \mathrm{~N} / \mathrm{mm}^{2}$. Contact stress is accompanied by a compression of the materials of the bushings. On the local areas of the bushing made of aluminum alloy the value of $Y$-stress reaches $-65 \mathrm{~N} / \mathrm{mm}^{2}$.

Maximum stress (Z-stress) is concentrated on the end surface of the bushing made of alloy steel on the part application of force of pressing-in. The value of Z-stress in this area reaches $85 \mathrm{~N} / \mathrm{mm}^{2}$. Bushing made of alloy steel exposed to tensile, the bushing made of aluminum alloy exposed to compression.

In accordance with the contours of von Mises stress, the reliability of the interference fit is ensured. The value of the von Mises stress on the contact surfaces of the bushings varies in the range from 0.5 $\mathrm{N} / \mathrm{mm}^{2}$ to $20 \mathrm{~N} / \mathrm{mm}^{2}$. The von Mises stress over of $50 \mathrm{~N} / \mathrm{mm}^{2}$ concentrated on the end surfaces of the bushings.

The change of direction of the velocity of deformation of the materials is presented in the form of vectors hosted on wire models of the pressing-in bushings (Fig 3). 


\begin{tabular}{|c|c|c|c|c|c|c|}
\hline Impact Factor: & $\begin{array}{l}\text { ISRA (India) } \\
\text { ISI (Dubai, UAE } \\
\text { GIF (Australia) } \\
\text { JIF }\end{array}$ & $\begin{array}{l}=1.344 \\
=0.829 \\
=0.356 \\
=1.500\end{array}$ & $\begin{array}{l}\text { SIS (USA) } \\
\text { PИНЦ (Russia) } \\
\text { ESJI (KZ) } \\
\text { SJIF (Morocco) }\end{array}$ & $\begin{array}{l}=0.912 \\
=0.179 \\
=1.042 \\
=2.031\end{array}$ & ICV (Poland) & $=6.630$ \\
\hline
\end{tabular}

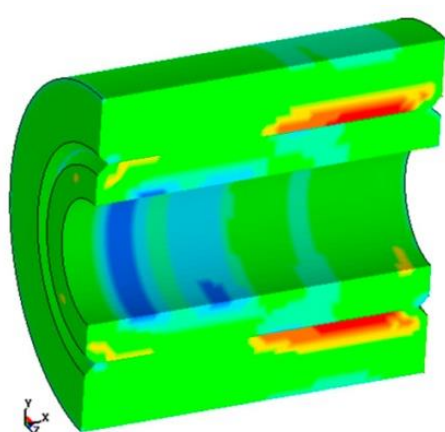

(A)

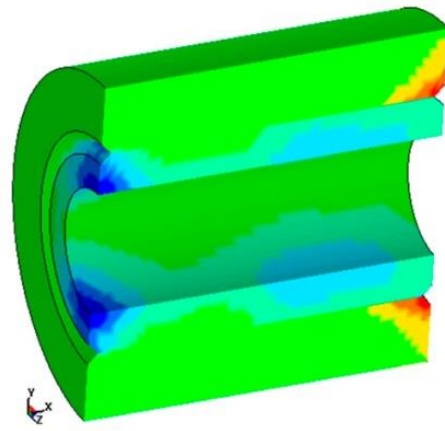

(C)

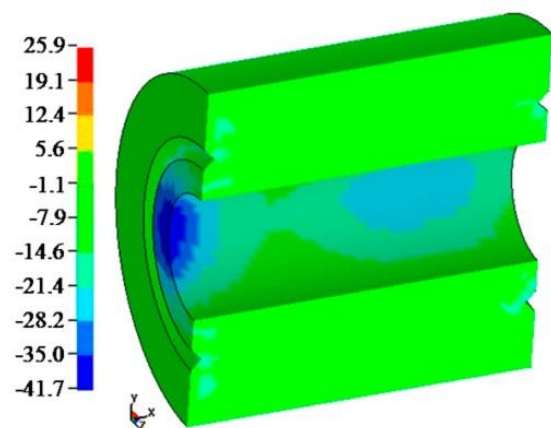

(B)
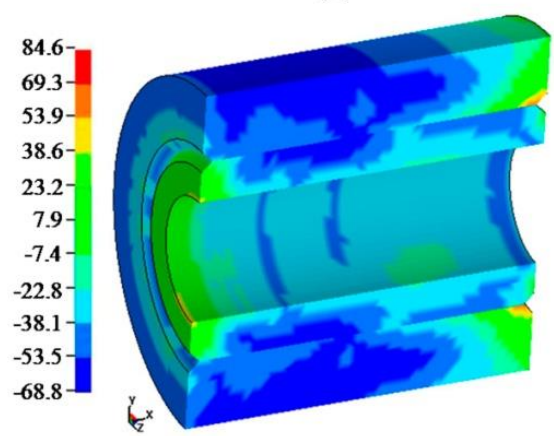

(D)
$92.8-$
$83.6-$
$74.3-$
$65.1-$
$55.9-$
$46.7-$
$37.4-$
$28.2-$
$19.0-$
$9.8-$
0.5
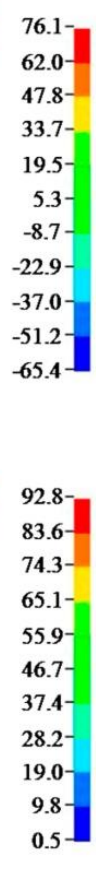

Figure 2 - (A) Contours of X-stress, (B) Contours of Y-stress, (C) Contours of Z-stress, (D) Contours of effective stress (von Mises stress). Unit of measurement: N/mm².

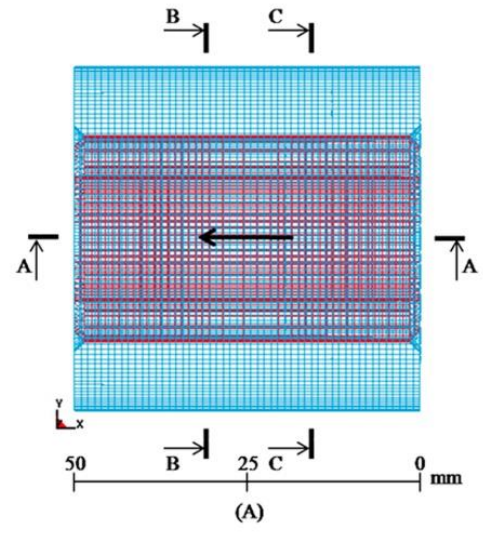

B-B

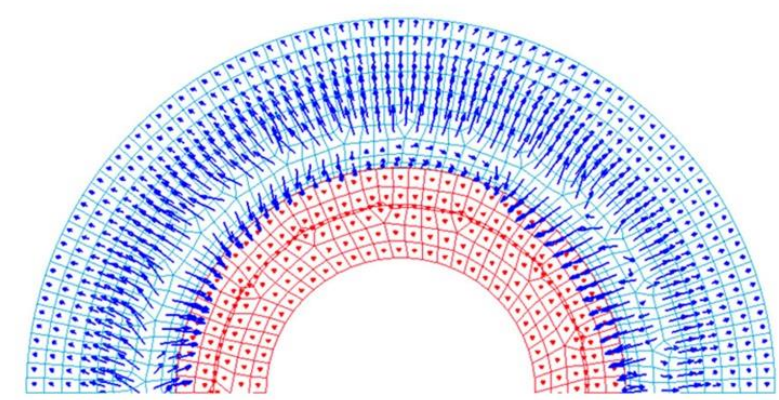

(C)

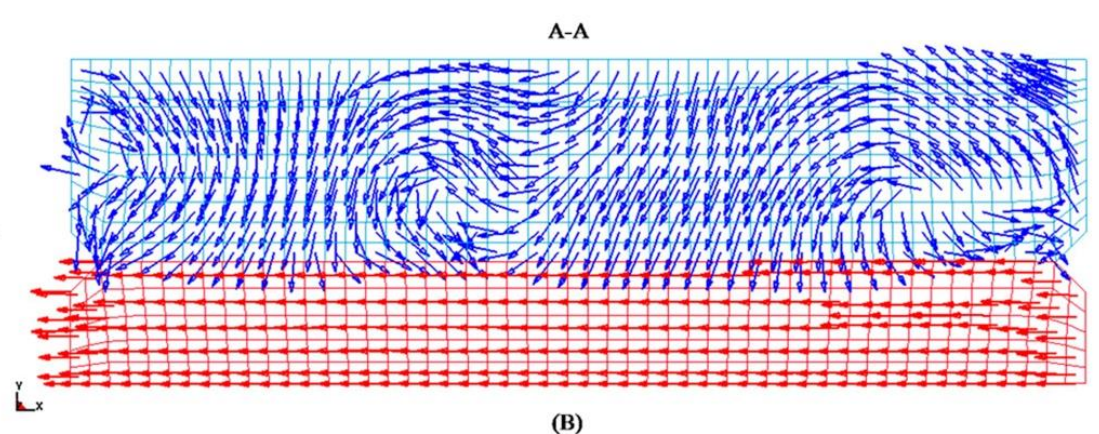

C-C

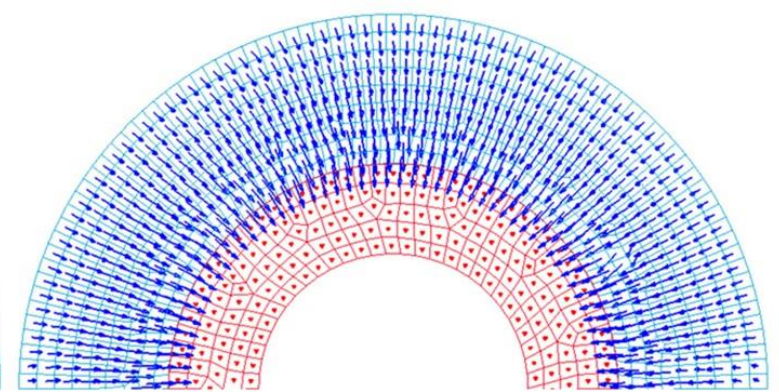

(D)

Figure 3 - (A) The orientation of the solid models of the bushings after simulation of the process of pressingin. The arrow indicates the direction of the efforts of pressing-in. (B) Velocity vector in the longitudinal cross section A-A of the bushings (the increase 3 times). (C) Velocity vector in the transverse cross section B-B of the bushings (the increase 2 times). (D) Velocity vector in the transverse cross section $\mathrm{C}-\mathrm{C}$ of the bushings (the increase 2 times).

ISPC Science and Education, 
The direction of the velocity of deformation of the bushing made of aluminum alloy coincides with the direction of the action of the force of pressing-in. Velocity of deformation of the bushing made of aluminum alloy is 70 to $80 \mathrm{~mm} / \mathrm{s}$. The direction of the velocity of deformation of the bushing made of alloy steel occurred in three axes in the transverse cross section of the interference fit at a distance of $30.5 \mathrm{~mm}$ from the end surfaces of the details: the contact surface layers of material exposed to compression; the surface layers of the material located at the outer diameter are practically not deformed; the layers of material located between the surface layers exposed to tensile. All layers of alloy steel compressed in the transverse cross section of the interference fit at a distance of $12 \mathrm{~mm}$ from the end surfaces of the details. Velocity of deformation of the bushing made of alloy steel is $8 \mathrm{~mm} / \mathrm{s}$, i.e. 10 times less than velocity of deformation of the bushing made of aluminum alloy.

The kinetic/internal energy ratio expended on the process of pressing-in of the bushings from the time presents in the form of dependences in Fig 3.

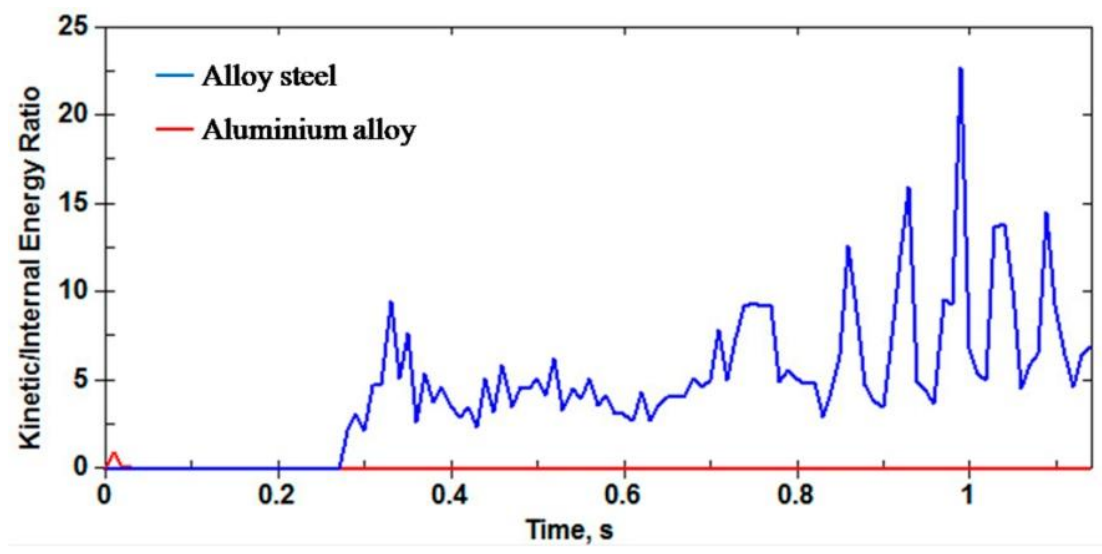

Figure 4 - The dependence of kinetic/internal energy ratio expended on the process from time of pressing-in.

The total energy expended on the process of pressing-in, is the sum of kinetic and internal energies. The graph shows that kinetic/internal energy ratio expended on the deformation of the bushing made of alloy steel (overcoming the forces of resistance and friction) increases with time. This contributes to increasing the area of the mating contact surfaces of the details when moving of the bushing made of aluminum alloy.

\section{CONCLUSION}

On the basis of the analysis of the results of the simulation of the process of pressing-in of the bushing made of aluminum alloy into of the bushing made of alloy steel we can draw the following conclusions:

The maximum stress and hence the friction force that occurs in the material of the bushings on the coordinate axes $\mathrm{X}$ and $\mathrm{Z}$. This ensures a strength of interference fit under the action of loads in axial and radial directions.

Velocity of deformation of the bushing made of alloy steel less than of the bushing made of aluminum alloy. The direction of the velocity of deformation chaotic for a bushing made of alloy steel.

Expended energy on the deformation of the bushing made of alloy steel reaches a maximum on 1 $\mathrm{s}$ of the process of pressing-in.

\section{References:}

1. Redreev GV, Popov SD, Redreev PG, Rusanov AN (2015) The reliability of thin-walled parts in an interference fit. Digital Scientific Magazine «Modern Problems of Science and Education», 1-2 (72): $67-73$.

2. Chemezov DA (2015) Deformations of the contact surfaces of the parts when pressing-in.
International Scientific Journal «Theoretical \& Applied Science», 2 (22): 1 - 7. SOI: http://s-oi.org/1.1/TAS*02(22)1 DOI: http://dx.doi.org/10.15863/TAS.2015.02.22.1

3. Ryazantseva IL (2008) The contact pressure in pressure couplings consisted of parts of 


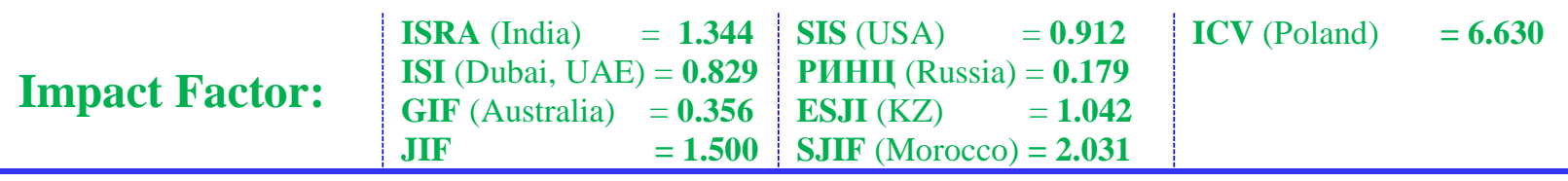

different length. «Omsk Scientific Bulletin», 2 (68): $33-37$.

4. Matlin MM, Barabanov GP, Kazankina EN, Kazankin VA (2009) Analysis of the influence of different factors on the real contact area interference fit. Journal «Izvestia VSTU», 11 (59): $88-91$.

5. Matlin MM, Kazankina EN, Kazankin VA (2010) Research of the dependence of the actual tightness on the parameters of the press-fit connection. Journal «Izvestia VSTU», 4 (64): $110-112$.

6. (2015) Mehanicheskie svoystva aluminievyh splavov. Available: http://aluminium- guide.ru/mexanicheskie-svojstvadeformiruemyx-alyuminievyx-splavov/ (Accessed: 23.08.2015).

7. (2015) Mehanicheskie svoystva staley. Available:

http://www.dpva.info/Guide/GuideMatherials/ Metalls/SteelsAndSteelAlloys/SteelProperties/ (Accessed: 23.08.2015).

8. (1999) LS-DYNA keyword user's manual. Nonlinear dynamic analysis of structures. Livermore Software Technology Corporation. pp. 1130. 